\section{Intermediate filament cycles}

\section{from Brian Anderton}

RESEARCH into the structure and organisation of the distinct fibrous organelles which make up the cytoskeleton of eukaryotic cells has intensified enormously in the past four or five years. The latest component of the cytoskeleton to come under close scrutiny is the intermediate filament. Intermediate filaments are approximately $10 \mathrm{~nm}$ in diameter and are so called because their width lies between those of the other two cytoskeletal fibres, microtubules (24 nm) and microfilaments $(6 \mathrm{~nm})$. Unlike tubulin and actin, which are the principal structural proteins of microtubules and microfilaments respectively, intermediate filament proteins seem not to be highly conserved and show a certain degree of tissue specificity. They have been divided into subclasses on the basis of biochemical and immunochemical data and with the inevitable consequence of isolation, the constituent proteins have been given names (in some cases more than one).

Five subclasses have been identified and new ones may need to be added. So far the (roughly tissue-specific) subclasses comprise (1) prekeratin tonofilaments of epithelial cells; (2) desmin or skeletin filaments of smooth muscle which are also identified with the protein present in the z-line region of cardiac and skeletal muscle; (3) filaments of fibroblasts and other mesenchymal cells (vimentin or decamin); (4) neurofilaments of neurones; and (5) glial filaments (glial fibrillary acidic protein) present in astrocytes (but not other glial cells). Structural homologies between different intermediate filaments have only occasionally been sought but some do seem to exist (Gard et al. Proc. natn. Acad. Sci. U.S.A. 76, 3894; 1979; Steinert et al. Proc. natn. Acad. Sci. U.S.A. 75, 6098; 1978).

The biochemical characterisation of different intermediate filaments has been hampered by the fact that when isolated they are mostly insoluble in salt solutions. This unfortunate physical behaviour from the point of view of the biochemist now seems to have been overcome by Zackroff and Goldman (Proc. natn. Acad. Sci. U.S.A. 76, 6226; 1979). Goldman and his colleagues have for some time been studying the fibroblast intermediate filaments from cells of the baby hamster kidney line BHK-21 and have shown that the main constituents are two polypeptides with chain weights of 54,000 and 55,000 which they have called decamin. In their latest paper they report a detailed investigation of an earlier observation that BHK-21 intermediate filaments disassemble on prolonged exposure to solutions of low ionic strength at around

Brian Anderton is a lecturer in the Department of Immunology, St. George's Hospital Medical School, London. neutral $p \mathrm{H}$ and reassemble on returning the protein to physiological ionic strength. When disassembled the material seems to consist of short rods or protofilaments perhaps $50 \mathrm{~nm}$ long and about half the width of an intermediate filament; the authors make no estimate as to the number of polypeptides constituting a single protofilament.

Turbidimetric measurements during reassembly show the process to be biphasic. Examination by electron microscopy suggests initial lateral association of the short thin rods to produce short thick rods followed by elongation of the latter to give apparently reconstituted intermediate filaments. The assembly process exhibits a critical protein concentration for initiation in the range $0.05-0.15 \mathrm{mg} \mathrm{ml}^{-1}$. Possibly the most significant aspect of the work is the discovery that cycles of disassembly/reassembly can be achieved, although protein recovery seems problematical, and that after two such cycles the stoichiometry of the $54 \mathrm{~K}$ and $55 \mathrm{~K}$ polypeptides seems to remain around unity and several high molecular weight proteins above 250,000 copurify with the decamin polypeptides. This approach of inducing cycles of polymerisation/depolymerisation has been used successfully for purifying tubulin and identifying microtubuleassociated proteins which remain in a constant weight ratio to the tubulin through repeated cycles. No doubt this report from Goldman's laboratory will now encourage others to apply the same technique in attempts to define the molecular composition of intermediate filaments from different sources. It should be pointed out, however, that Zackroff and Goldman believe the large decaminassociated polypeptides not to be essential for intermediate filament assembly since their removal by mild proteolysis does not block polymerisation of the $54 \mathrm{~K}$ and $55 \mathrm{~K}$ decamin polypeptides.

It remains to be seen whether or not the BHK-21 fibroblast intermediate filaments are heteropolymers of the $54 \mathrm{~K}$ and $55 \mathrm{~K}$ chains or if homopolymers of each exist separately inside the cell. Lazarides and colleagues have suggested that muscle intermediate filament protein, which they call desmin, is not restricted to muscle in its distribution but is also found in nonmuscle cells such as fibroblasts, including BHK-21 cells (Proc. natn. Acad. Sci. U.S.A. 76, 3894; 1979). They have assigned the $54 \mathrm{~K}$ polypeptide from BHK-21 cells to desmin and the $55 \mathrm{~K}$ polypeptide to the true fibroblast intermediate filament protein. They have also recently claimed that fibroblast intermediate filament protein too is more widely distributed than hitherto assumed and that it occurs along with desmin in the myofibril z-disc (Cell 18, $1053 ;$ 1979). Notwithstanding earlier reports that desmin was absent from nonmuscle cells, these more recent data seem convincing and are analogous to the results from Franke's, Weber's and Osborn's laboratories which show that epithelial cells also contain two types of intermediate filament, namely prekeratin tonofilaments and fibroblast intermediate filaments for which they use the name vimentin filaments (Differentiation 14, 35; 1979). However, more studies are needed as the BHK-21 cell line may not be typical. It is unclear, for instance, whether mouse 3T3 cells contain two types of intermediate filament polypeptide as published electrophoretic patterns (Franke et al. op. cit.) of purified intermediate filament protein from these latter cells show a single prominent polypeptide and not a doublet like that found from the BHK-21 cells.

Although such ambiguities remain, the classes and distribution of intermediate filaments are now beginning to fall into a pattern although we remain mostly in the dark as to their function. Probably the predominant view is that they are important in maintaining cell shape and the spatial organisation of other intracellular structures. However, now that they promise to be amenable to biochemical investigations of the type used by Zackroff and Goldman, their lack of established function is unlikely to deter the protein biochemists.

\section{Kimberlite and carbonatite magmas}

from $K$. G. Cox

THE Earth's crust is a relatively thin layer made up of familiar rocks similar to those seen at the surface. However, at a depth of about $10 \mathrm{~km}$ in oceanic areas and at $50 \mathrm{~km}$ beneath the continents a sudden increase in the velocity of seismic waves marks a fundamental change of structure. From here downwards, to the outer edge of the core at a depth of about $3,000 \mathrm{~km}$, the rocks are referred to as the mantle. This is volumetrically by far the largest compositional component of the Earth but relatively little of a direct nature is known about it. The mantle $50 \mathrm{~km}$ below our feet is distinctly less accessible than the Moon. Apart from the very uppermost levels of the mantle, which are occasionally exposed at the surface as a result of violent continental collisions, the only samples available are brought to the surface as fragments ('nodules') suspended in magma during volcanic activity. The distinctly rare volcanoes known as kimberlite pipes, which of course also supply diamonds, are the richest source of such materials.

At a recent meeting in London* J.B. Dawson (University of Sheffield) gave an authoritative review of the present state of knowledge of upper mantle rocks derived as nodules from kimberlite pipes, largely from southern Africa.

*The Anniversary Meeting of the Mineralogical Society, held in London on 10 January focused on the petrology of mantle carbonatite. 